\title{
Editorials
}

\section{How do we identify and support maltreated children?}

GPs know that accurate up-to-date recording of important diagnoses in primary care, using searchable codes, improve the quality of care due to better and more timely targeting of interventions and improved monitoring. Information systems have the potential to transform care. Although not without their criticism, the computerisation of the referral process means that it has been possible to measure and monitor the wait from referral to treatment, and potentially to improve the process. ${ }^{2,3}$

\section{RECORDING MALTREATMENT}

Improved recording is also critical for policy, for exploring reasons for variation in care, and, in the reformed NHS, it will provide essential information for clinical commissioning groups and the NHS Commissioning Board, where routine data can be used to inform the public health agenda, especially when they contain or can be linked to outcome data. Research databases such as QRisk, the Health Improvement Network, and the General Practice Research Database (Now known as The Clinical Practice Research Datalink) are excellent examples of how routine data may be used to measure quality health outcomes. $^{4}$

These potential benefits are yet to be realised in GPs' responses to vulnerable children and young people who give rise to concerns about possible abuse or neglect. A recent study in the $B J G P^{5}$, shows that rates of recording child maltreatment concerns using Read Codes remain well below those expected. An evaluation of the feasibility of standardised coding in 11 practices is in progress (the codes used in the pilot study are available online at: http://www. clininf.eu/childmaltreatment-codes.html). If successful, wider implementation should be accompanied by robust evaluation studies.

\section{PRIMARY CARE TEAM RESPONSE}

The primary healthcare team is particularly important for recognising and responding to children with neglect. Despite the impact on the child, the complex, ongoing and cumulative nature of neglect means that these children may not reach thresholds for formal child protection services. ${ }^{6}$ Even when problems have been identified, the primary care team is the main or only service contact for these children, especially for preschool children.
Understanding how the primary care team responds when concerns are raised about possible neglect and other forms of maltreatment is critical to understanding the way in which health care can contribute to recognition, monitoring, and care of maltreated children. First, children in the UK present frequently to primary care: children under 5 years old consult their GP an average of five times a year, ${ }^{7}$ and about 1 in 13 children and young people will have seen their GP in the last 2 weeks. ${ }^{8}$

Second, the primary care team has insight into both risk factors and protective factors for child maltreatment and the functioning of the family. This is because GPs usually provide care for the mother and siblings, and often for the father and extended family. They are well placed to monitor and respond to domestic violence, depression, drug or alcohol abuse, and signs in family members of stress, trauma, and failing in parenting, through their therapeutic relationships with the child and parent.

Third, GPs hold a continuous healthcare record for the child, as well as for other family members, so that even if patients rarely see the same GP, concerns and past problems are all documented in the patient's record. No other services have such longitudinal insights for multiple family members.

Fourth, as child maltreatment is often a chronic condition, the primary care team can play a key role in anticipating stressors for vulnerable families and initiating support or therapeutic services.

Finally, research consistently shows that a substantial proportion of maltreated children (or members of their family) have chronic medical problems or disability. ${ }^{6}$ The primary care team can play a critical role in addressing health problems on an ongoing basis. This continuity of care is particularly important for the most vulnerable families, who may spend periods of time being monitored and supported by children's social care services (for example, on a child protection plan), but who may nevertheless require ongoing support, possibly throughout childhood, with a focus on health needs. What is needed is the provision of long-term support to address health and welfare needs for vulnerable families with accurate continuous longitudinal recording of information on GP systems.

\section{WIDER RESOURCES AND DATA MANAGEMENT}

There are many strands of care around maltreatment that affect both how data are recorded and used by primary care. This reflects the organisation and functioning of the primary care team, the role of multidisciplinary team meetings and interactions between team members, and engagement with children and families. Interfacing with services outside health allows for holistic information sharing and accessing service provision for vulnerable children and families. It reflects the increased requirement for prioritising the most needy, assessing outcomes, and being answerable when children 'slip through the net' or even 'stay in the net' without recognisable improvement. Data recording issues will need to address ethics, confidentiality, and minimum data set recording considerations, particularly if there are shared information systems between GPs, health visitors, and social services.

It is clear that GPs actively address maltreatment concerns, but often enter free text or saved documents, neither of which can be easily searched electronically. Search ability is critical for managing parents, children, and their siblings, but also for enabling sharing of information and partnership working with multiagency teams, as advocated by the Munro Review

\section{Understanding how the primary care team responds when concerns are raised about possible neglect and other forms of maltreatment is critical to understanding the way in which healthcare can contribute to recognition, monitoring, and care of maltreated children.}




\section{"GPs may fear being challenged about or asked to justify why if they record concerns and then do not contact social care, a factor which may lead to GPS not to code their concerns...}

On Child Protection. " The benefits of improved recording are obvious but there are also potential harms. The difficulties of open access to records by, for example, midwives or health visitors, managing parents and children when codes are visible on the screen in the surgery, and of children wanting to see their records lalthough this applies to free text too) are self-evident. Woodman et al describes the process of choosing preferred codes which would be least likely to be contentious. ${ }^{5} \mathrm{GPs}$ may fear being challenged about or asked to justify why if they record concerns and then do not contact social care, a factor which may lead to GPs not to code their concerns leven though NICE guidance states they should record 'consider' maltreatment as part of the differential diagnosis [as opposed to 'suspecting'] but for this level of concern would not necessarily notify social care).

There is a need for further exploration of coding for maltreatment in primary care, which looks at the perceived harms and the reasons why GPs either do not code or do not want to code. Routine data give us some information about variation in care, and potential insights into whether that variation is likely to be acceptable; for example, because it can be explained by the demographics of a population or its degree of deprivation, or possibly due to poor care. If there are no data it is not possible to know much about quality other than through complaints or critical incidents. Information systems provide the potential to transform care for vulnerable groups of patients.

\section{Simon de Lusignan,}

Professor of Primary Care \& Clinical Informatics, Chair in Health Care Management, Department of Health Care Management \& Policy, University of Surrey, Guildford.

\section{Janice Allister,}

RCGP Clinical Champion for Child Health, RCGP Clinical Innovation and Research Centre, Royal College of General Practitioners, London.

\section{Imran Rafi,}

Medical Director RCGP Clinical Innovation and Research Centre, Royal College of General

Practitioners, London.

\section{Provenance}

Freely submitted; externally peer-reviewed.

\section{Acknowledgements}

We thank Professor Ruth Gilbert and Jenny

Woodman for their comments on earlier drafts.

\section{Competing interests}

Simon de Lusignan, Janice Allister, and Imran Rafi are all collaborators in a Royal College of GPs and UCL (institute of Child Health) in safeguarding project.

DOI: 10.3399/bjgp12X654461

\section{ADDRESS FOR CORRESPONDENCE}

\section{Imran Rafi}

Royal College of General Practitioners, Clinical Innovation and Research Centre, 1 Bow Churchyard, London, EC4M 9DQ, UK.

E-mail: irafiđrcgp.org.uk

\section{REFERENCES}

1. de Lusignan S. The optimum granularity for coding diagnostic data in primary care report of a workshop of the EFMI Primary Care Informatics Working Group at MIE 2005. Inform Prim Care 2006; 14(2): 133-137.

2. Rashid M, Abeysundra L, Mohd-Isa A, et al. Two years and 196 million pounds later: where is Choose and Book? Inform Prim Care 2007; 15(2): 111-119.

3. Parmar V, Large A, Madden C, Das V. The online outpatient booking system 'Choose and Book' improves attendance rates at an audiology clinic: a comparative audit. Inform Prim Care 2009; 17(3): 183-186.

4. de Lusignan S, van Weel C. The use of routinely collected computer data for research in primary care: opportunities and challenges. Fam Pract 2006; 23(2): 253-263.

5. Woodman Allister J, Rafi I, de Lusignan S, et al. A simple approach to improve recording of concerns about child maltreatment in primary care records: developing a quality improvement intervention. $\mathrm{Br} J$ Gen Pract 2012; DOI: 10.3399/bjgp12X652346.

6. Brandon M, Belderson P, Warren C, et al The preoccupation with thresholds in cases of child death or serious injury through abuse and neglect. Child Abuse Review 2008; 17(5): 313-330.

7. Jones R, Flaherty EG, Binns HJ, et al. Clinicians' description of factors influencing their reporting of suspected child abuse: report of the Child Abuse Reporting Experience Study Research Group. Pediatrics 2008; 122(2): 259-266.

8. Ayre P. Significant harm: making professional judgements. Child Abuse Review 1998; 7(5): 330-342.

9. Munro E. The Munro review on child protection: interim report. The child's journey. London: Department of Education, 2011. 